\title{
A Novel Imidazoline Derivative Used as an Effective Corrosion Inhibitor for Carbon Steel in a $\mathrm{CO}_{2} / \mathrm{H}_{2} \mathrm{~S}$ Environment
}

\author{
Yuan Lu ${ }^{1}$, Wei Wang ${ }^{1}$, Chen Zhang ${ }^{2}$ Jingmao Zhao ${ }^{1,3, *}$ \\ ${ }^{1}$ College of Material Science and Engineering, Beijing University of Chemical Technology, Beijing \\ 100029, China \\ ${ }^{2}$ Sinopec Marking South China Company, Guangzhou 510620, China \\ ${ }^{3}$ Beijing Key Laboratory of Electrochemical Process and Technology for Materials, Beijing 100029, \\ China \\ *E-mail:jingmaozhao@126.com
}

doi: $10.20964 / 2019.09 .06$

Received: 4 May 2019/ Accepted: 16 June 2019 / Published: 31 July 2019

\begin{abstract}
Thioureido-oleic acid imidazoline, TAI, is widely used in the oil/gas industry as an effective corrosion inhibitor to protect carbon steel pipelines from $\mathrm{CO}_{2}$ corrosion. However, the inhibition efficiency is significantly reduced when $\mathrm{H}_{2} \mathrm{~S}$ gas coexists with $\mathrm{CO}_{2}$. In this study, the imidazoline was modified by reaction with formaldehyde and propynyl alcohol to develop a modified imidazoline (MTAI). The inhibition performance was evaluated by dynamic weight loss, potentiodynamic polarization, contact angle, and scanning electron microscopy (SEM) measurements as well as quantum chemical calculations. Dynamic corrosion tests and polarization measurements show that the inhibition efficiency of MTAI is significantly better than that of TAI in a $\mathrm{CO}_{2} / \mathrm{H}_{2} \mathrm{~S}$ environment. The contact angle measurements show that the MTAI inhibitory film is more hydrophobic than the TAI film. The quantum chemical calculations demonstrate that MTAI has two adsorption centres, which make the adsorption more stable and thus the inhibition more efficient.
\end{abstract}

Keywords: $\mathrm{CO}_{2} / \mathrm{H}_{2} \mathrm{~S}$ corrosion; imidazoline; corrosion inhibitor; weight loss; polarization curve; contact angle; adsorption; quantum chemical calculation

\section{FULL TEXT}

(C) 2019 The Authors. Published by ESG (www.electrochemsci.org). This article is an open access article distributed under the terms and conditions of the Creative Commons Attribution license (http://creativecommons.org/licenses/by/4.0/). 